
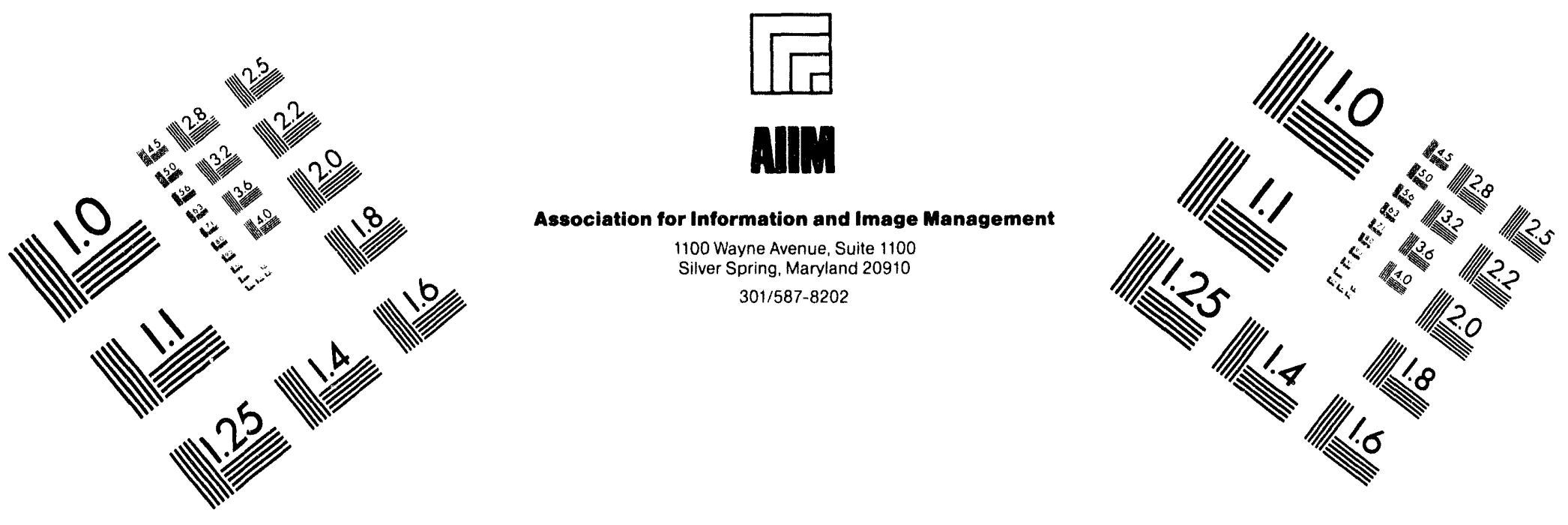

\title{
Centimeter
}

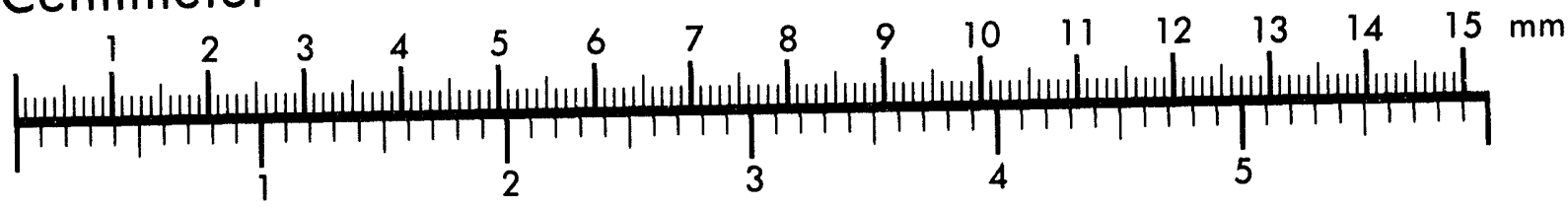
Inches
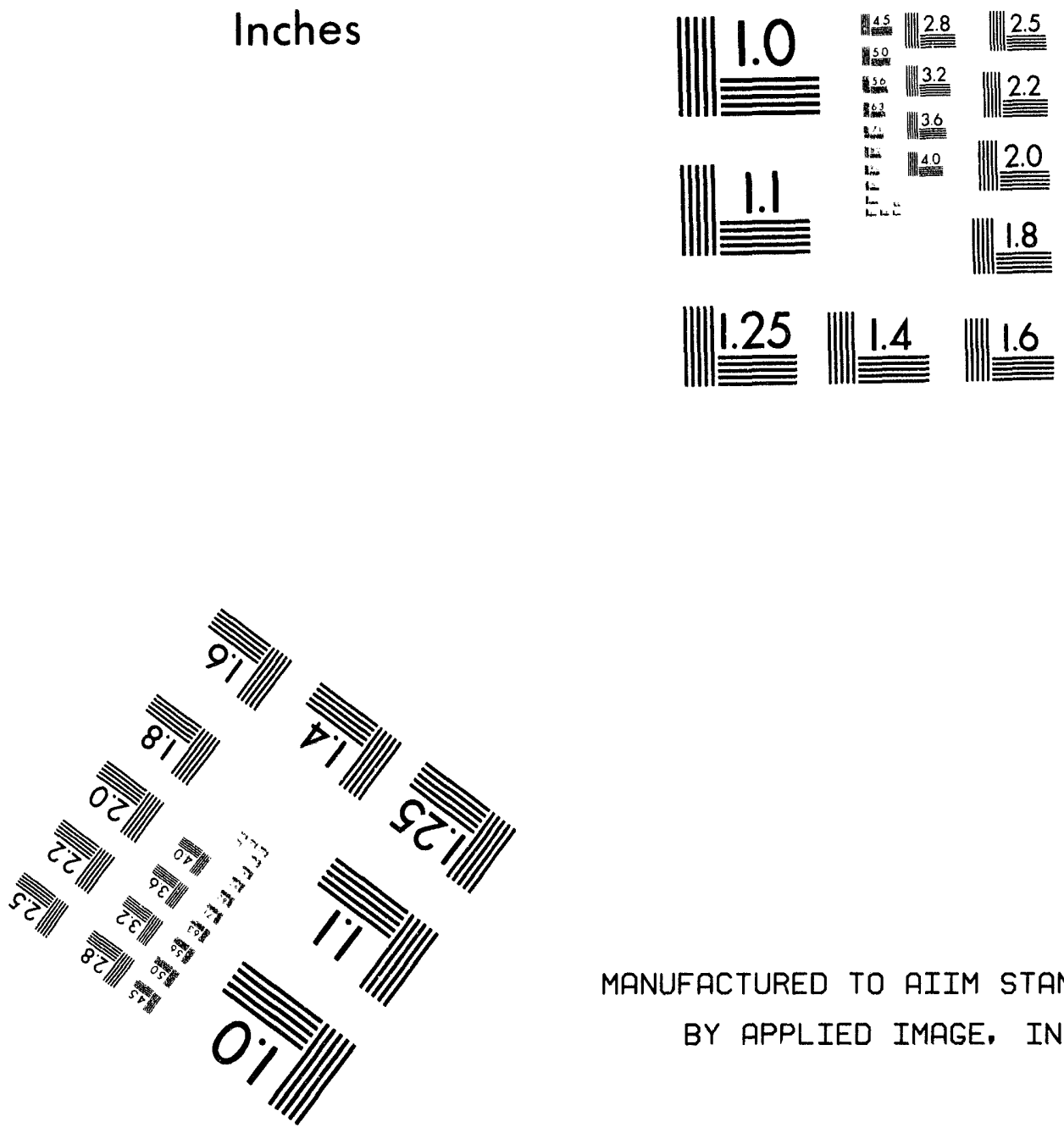

MANUFACTURED TO AIIM STANDARDS BY APPLIED IMAGE. INC.

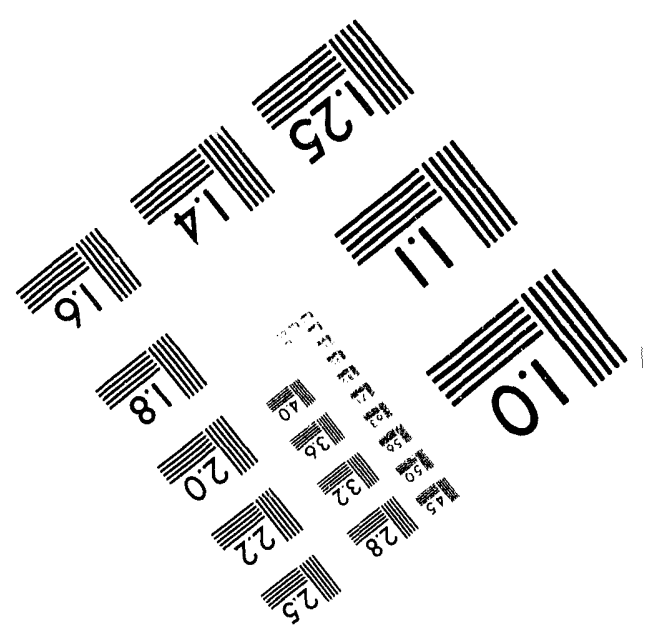



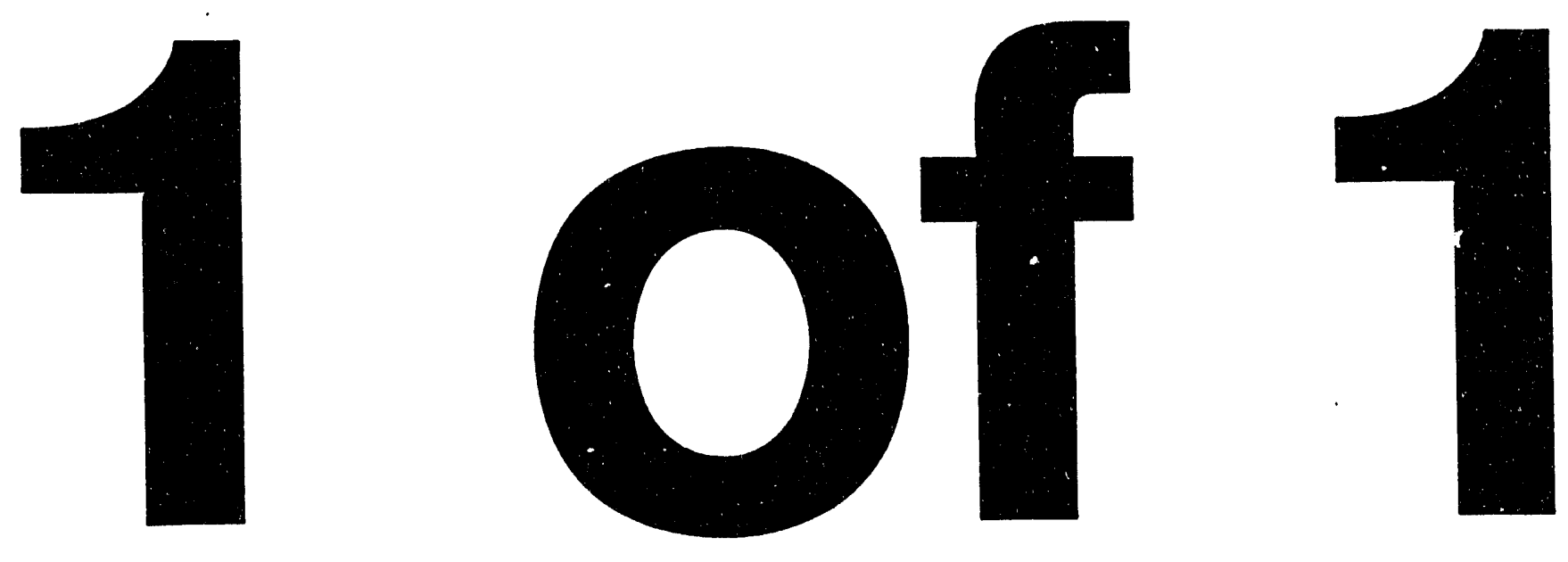


\title{
CoNF $940753--18$
}

Note: This is a preprint of a paper submitted for publication. Contents of this paper should not be quoted or referred to without permission of the author(s).

For publication in

Proceedings of the 52nd Annual Meeting of the Microscopy Society of America, New Orleans, Louisiana, July 31-August 5, 1994

\section{DIRECT RETRIEVAL OF CRYSTAL STRUCTURES BY MAXIMUM ENTROPY ANALYSIS OF INCOHERENT Z-CONTRAST IMAGES}

\author{
A. J. McGibbon and S. J. Pennycook \\ Solid State Division \\ Oak Ridge National Laboratory \\ Oak Ridge, Tennessee 37831-6031
}

\begin{abstract}
"The submitted manuscript has been suthored The submitted manuscript has been suthored conirace No. DE.ACOS-840R21400. Accordingly, the U.S. Government retains Accordingly, the U.S. Government retains nonexclusive, royalty-free license to publish or contribution, or sllow others to do so, for U.S. Government purposes."
\end{abstract}

\author{
SOLID STATE DIVISION \\ OAK RIDGE N.ATIONAL LABORATORY \\ Managed by \\ MARTIN MARIETTA ENERGY SYSTEMS, INC. \\ under \\ Contract No. DE-AC05-84OR21400 \\ with the \\ U.S. DEPARTMENT OF ENERGY \\ Oak Ridge, Tennessee
}

March 1994

\section{MASTER}


Solid State Division, Oak Ridge National Laboratory, P. O. Box 2008, Oak Ridge, TN 37831. USA

Z-contrast imaging' of crystalline specimens in a scanning transmission electron microscope (STEM) can provide directly interpretable images of crystal structures at atomic resolution with strong compositional sensitivity. The key feature of the technique is that, by recording images using high-angle thermally diffuse scattered electrons, the resultant image is incoherent, and can be interpreted as a convolution between the incident electron probe and the projected crystal stricture of the specimen. Consequently, the technique is ideally suited to the application of deconvolution routines which enable the retrieval cf the original crystal lattice by means of an incident electron probe approximation, and with no prior assumption of the nature of the crystal itself. Here, we show that by applying the image processing technique of maximum entropy, such a retrieval can be achieved with high accuracy, enhancing spatial resolution whilst preserving $\mathrm{Z}$-sensitivity.

Maximum entropy ${ }^{2}$ is an image processing routine based on Bayesian probability which produces a 'most likely' reconstruction of the original image given a particular point spread function, or in this case, electron probe current density distribution. The results described here were obtained using a VG Microscopes MaxEnt software routine on an IBM $486 \mathrm{PC}$ with special accelerator card. Experimentally acquired images were taken on a $300 \mathrm{kV}$ STEM at $1.3 \AA$ spatial resolution. As a measure of the capabilities of maximum eniropy in the analysis of Z-contrast images, the technique was applied to the study of simulated $300 \mathrm{kV}$ images of a graded SiGe structure in the $<110>$ orientation (Fig.1). Shown in figures 1(a) and (b) respectively is the original simulated image using the theoretical optimum probe and the full maximum entropy processed image obtained using a gaussian probe approximation. It can be scen that even with a simple probe approximation, the original crystal structure on which the simulation is based is retrieved in terms of an array of delta functions with coordinates that match those of the initial column positions to within $1 \%$. In addition, variations in signal intensity corresponding to columnar scattering power are preserved. The robust nature of the maximum entropy approach is demonstrated by processing simulations with increasing levels of noise (Figs $1 \mathrm{c}$ and $\mathrm{e}$ ) and retrieving the original structure (Figs $1 \mathrm{~d}$ and $\mathrm{f}$ ). These figures show that unless nearly all image information is lost, column positions can be retrieved to within an accuracy of $<10 \%$.

As-acquired 300kV Z-contrast images of Si and GaAs in the $\langle 110>$ orientation are shown in figures 2(a) and 3(a) respectively. Qualitatively, it can be seen that contained in these images alone is information on both column positions and composition at a resolution better than the nearest neighbor spacing. However, more accurate analyses can be obtained by applying maximum entropy to each image (figs $2 b, 2 c, 3 b$ and $3 c)$. The power of this approach is clearly demonstrated, showing that not only can coordinates be assigned to each column position, but also, in the case of $\mathrm{GaAs}$, that column intensity information enables the assignation of elemental species to specific column sites in the sublattice. In addition to the inaterials discussed here, maximum entropy has also been applied to the study of grain boundaries in $\mathrm{SrTiO}_{3}{ }^{3}$.

\section{References}

1. S. J. Pennycook and D. E. Jesson, Phys.Rev.Lett 64 (1990) 938

2. S. F. Gul! and J. Skilling, IEE proceedings $131 \mathrm{~F}$ (1984) 646

3. M.M. McGibbon et. al., (1994) elsewhere in this proceedings.

4. This research was sponsored by the Division of Materials Sciences, US Department of Energy contract DE-AC05-840R21400 with Martin Marietta Energy systems Inc, and by the Oak Ridge National Laboratory Postdoctoral Research Program administered by the Oak Ridge Institute for Science and Education.

\section{DISCLAIMER}

This report was prepared as an account of work sponsored by an agency of the United States This report was prepared as an acter employees, makes any warranty, express or implied, or assumes any legal liability or responsibility for the accuracy, completeness, or usefulness of any information, apparatus, product, or process disclosed, or represents that its use would not infringe privately owned rights. Reference herein to any specific commercial product, process, or service by trade name, trademark, manufacturer, or otherwise does not necessarily constitute or imply its endorsement, recommanufation, or favoring by the United States Government or any agency thereof. The views and opinions of authors expressed herein do not necessarily state or reflect those of the United States Government or any agency thereof. 

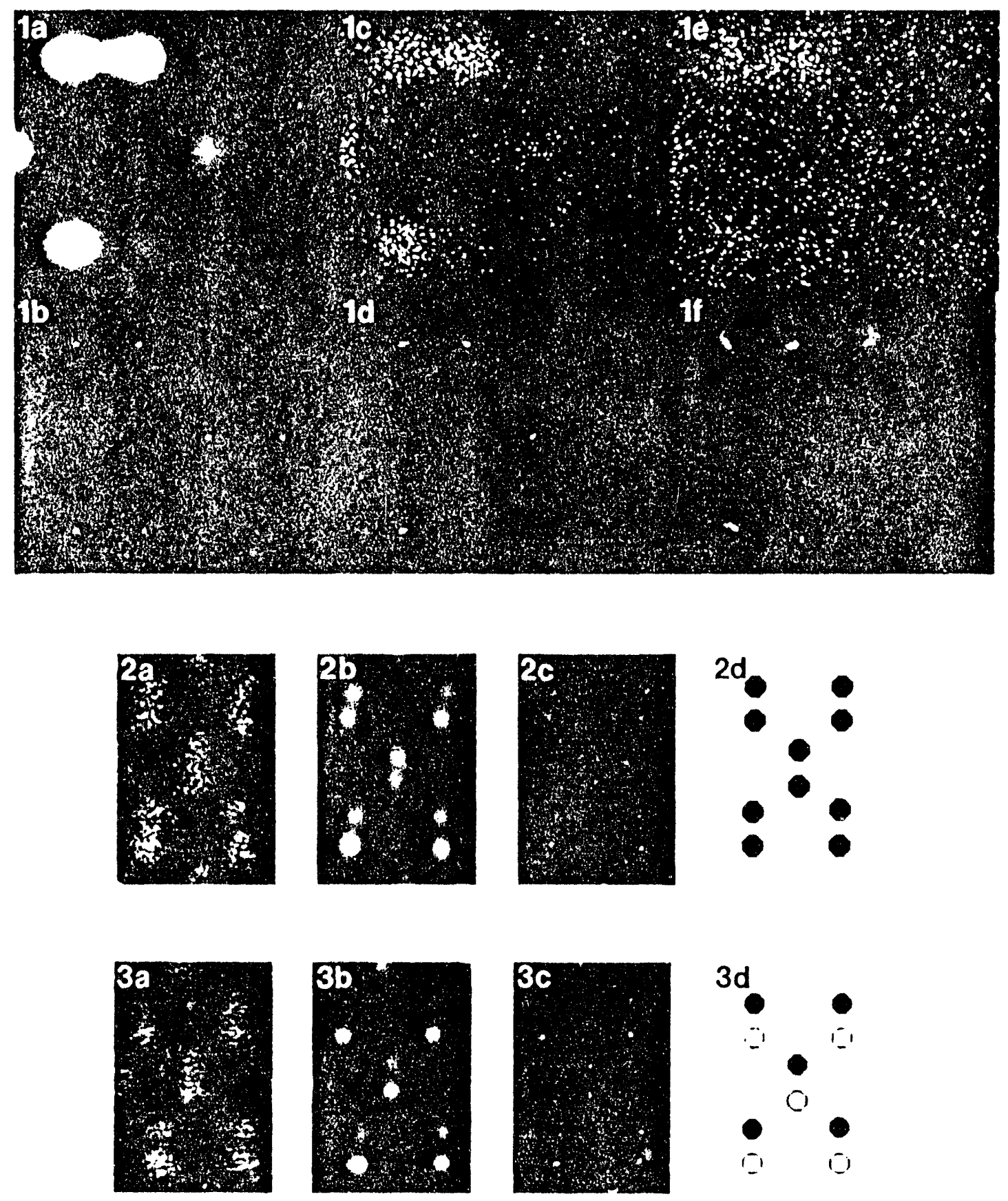

FIG. 1.Simulated Z-contrast images of a graded SiGe structure with increasing levels of noise (a, $c$ and $e$ ) and their corresponding maximum entropy images (b, $d$ and $f$ )

FIG. 2. (a) As-acquired, (b) partial and (c) full maximum entropy images and (d) schematic diagram of Si in the $<110>$ orientation.

FIG. 3. (a) As-acquired, (b) partial and (c) full maximum entropy images and (d) schematic diagram of GaAs in the $<110>$ orientation. 

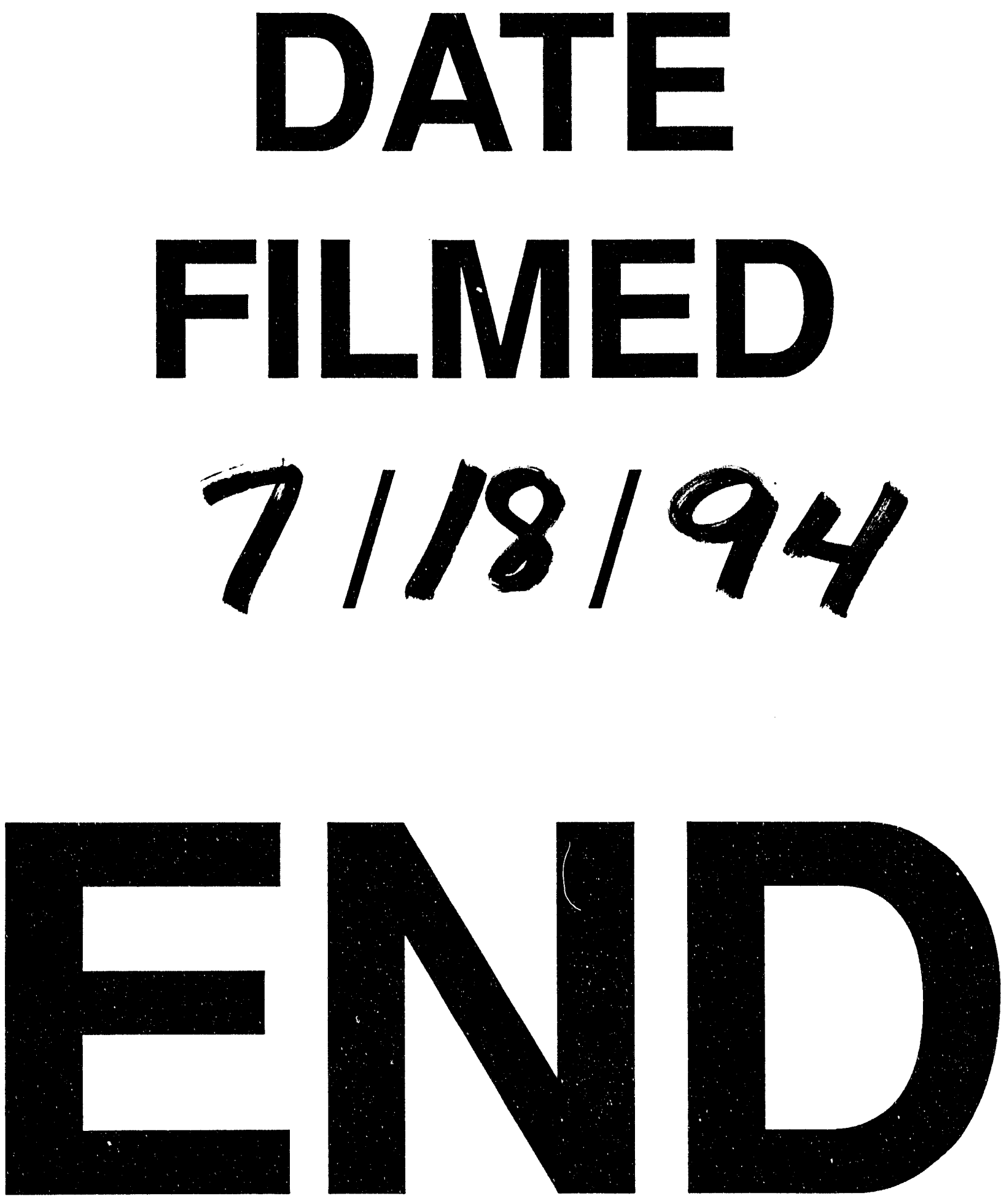

IV 
